\title{
Narrative Review of Soundscape Studies
}

\section{Julia Chieng \& Cheong Jan Chan}

To Link this Article: http://dx.doi.org/10.6007/IJARBSS/v11-i11/11652

DOI:10.6007/IJARBSS/v11-i11/11652

Received: 05 September 2021, Revised: 06 October 2021, Accepted: 26 October 2021

Published Online: 24 November 2021

In-Text Citation: (Chieng \& Chan, 2021)

To Cite this Article: Chieng, J., \& Chan, C. J. (2021). Narrative Review of Soundscape Studies. International Journal of Academic Research in Business and Social Sciences, 11(11), 1652-1672.

Copyright: () 2021 The Author(s)

Published by Human Resource Management Academic Research Society (www.hrmars.com)

This article is published under the Creative Commons Attribution (CC BY 4.0) license. Anyone may reproduce, distribute, translate and create derivative works of this article (for both commercial and non0-commercial purposes), subject to full attribution to the original publication and authors. The full terms of this license may be seen

at: http://creativecommons.org/licences/by/4.0/legalcode

Vol. 11, No. 11, 2021, Pg. $1652-1672$

http://hrmars.com/index.php/pages/detail/IJARBSS

JOURNAL HOMEPAGE

Full Terms \& Conditions of access and use can be found at http://hrmars.com/index.php/pages/detail/publication-ethics 


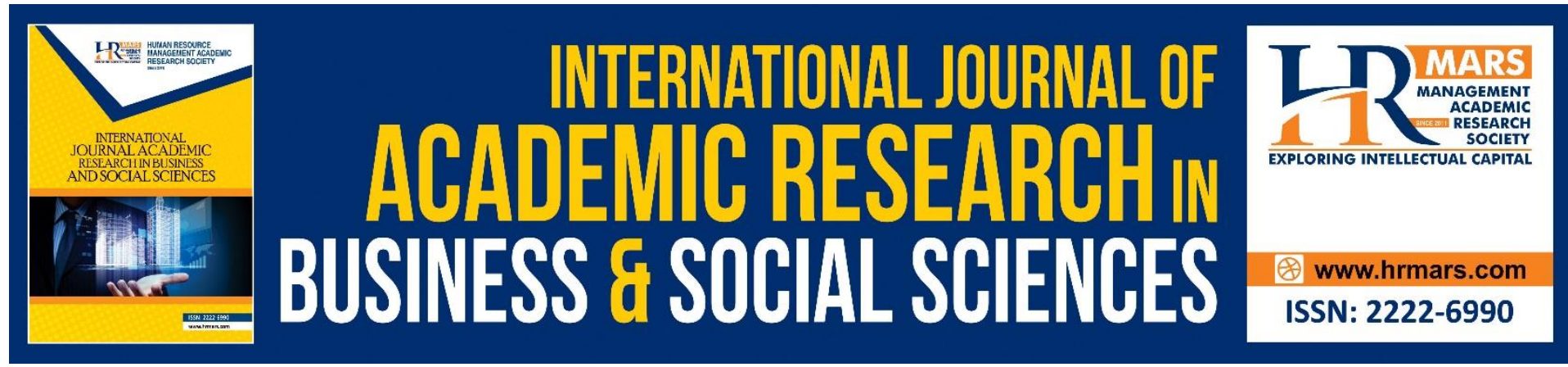

\title{
Narrative Review of Soundscape Studies
}

\author{
Julia Chieng \& Cheong Jan Chan \\ Department of Music, Faculty of Human Ecology, Universiti Putra Malaysia, 43400 UPM \\ Serdang, Selangor, Malaysia \\ Email: chiengjulia@upm.edu.my
}

\begin{abstract}
Soundscape generally refers to the sonic environment. The study of soundscape is significant to improve the quality of the environment, enhance the function of a place and promote a healthy and quality life as well as for the understanding of cultures. Given approximately half a century of scholarly studies on soundscape, the purpose of this conceptual paper is to present a narrative review of the literature on its definitions, methods, fields and space types from various disciplines to provide an overview and reference to novice soundscape researchers. As it is a wide-ranging field, soundscape study inherently encompasses research from multiple disciplines and mostly necessitates cross-disciplinary approaches. Among the diversity with different emphases on research frameworks and methodologies, soundscape research usually incorporates the three elements of acoustic properties, perception and place. The study can be for documentation, description, management and/or creation of soundscape. Some of the fields of soundscape study involve acoustic ecology, acoustemology, ecomusicology, acoustic engineering, artistic creativity or wellbeing. Data were usually collected through audio recordings, measurements of sound levels, soundwalks, questionnaires and interviews. Soundscape research has been increasing in America and European countries and can potentially be further expanded on different distinctive sound environments, ecosystems and sociocultural lifestyles.
\end{abstract}

Keywords: Acoustic Ecology, Sound Environment, Soundscape, Soundscape Perception, Sound Experience

\section{Definition Of "Soundscape"}

Since the 1960s, the scholarly study on soundscape has been developing from multiple perspectives. At present, the term "soundscape" has been used in different specialisations such as architectural design, acoustic engineering, landscape, environmental sciences, psychology, sonic arts, musicology and ethnomusicology. Some research necessitates studying soundscape using interdisciplinary methods. Besides being an emergent field of study, its complexity is due to its diversity in meaning and approaches. This article intends to present the different schools of soundscape studies in various contexts to provide an overview for novice researchers. As soundscape studies encompass various disciplines and methodologies, being able to navigate through these multiple aspects would provide more appropriate approaches and frameworks for the commencement of soundscape projects. 
"Soundscape" refers to a sonic environment. Sound is ranked second in significance when compared to other environmental factors such as wind, sun, temperature, security, air quality, view and humidity at a place (Kang \& Zhang, 2010, p. 156). Statistical results also showed that one-third of respondents viewed soundscape as the most important element in an environment (Meng, Kang \& Jin, 2013, p. 1007). In soundscape studies, any sound in an environment can be considered a useful resource with functional properties in delivering signals, messages, meanings and contexts. Soundscape can be used in entertainment, for therapy, as a commodity or as a sign of power.

Soundscape studies differ from environmental studies of sound management in the way that their aim goes beyond noise mitigation to include meaning and relationships between sounds, living things and places. In other words, rather than paying attention to the sound environment only when it is annoying and targeting mainly adverse sounds of certain decibels and frequencies that are deemed as unwanted waste to be eliminated, soundscape involves the study of the informativeness and pleasantness of any sound in an environment as well as creating a pleasant and meaningful soundscape in a place. Acoustics and a cultural study of soundscape can provide evidence of sound profiles and their interconnectivity with place and society. This leads to deeper understandings of the explicit and implicit meanings of sound features and subsequently its functionality in an environment.

The International Organization for Standardization (ISO) 12913-1:2014 stated that soundscape is an "acoustic environment as perceived or experienced and/or understood by a person or people, in context" (www.iso.org). The literature provides slightly different definitions of "soundscape" (Table 1). 
Table 1

Definitions of "soundscape" in different studies.

\begin{tabular}{ll}
\hline Author(s) & Definitions \\
\hline Schafer (1977/1994, p. 7) & $\begin{array}{l}\text { "The soundscape is any acoustic field of study. We may speak } \\
\text { of a musical composition as a soundscape, or a radio program } \\
\text { as a soundscape or an acoustic environment as a soundscape." }\end{array}$ \\
\hline Thompson (2002, p. 1) & $\begin{array}{l}\text { "Auditory or aural landscape ... simultaneously a physical } \\
\text { environment and a way of perceiving that environment; it is } \\
\text { both a world and a culture constructed to make sense of that } \\
\text { world" }\end{array}$ \\
\hline $\begin{array}{l}\text { Raimbault \& Dubois } \\
\text { (2005, p. 340) }\end{array}$ & $\begin{array}{l}\text { "The relationship between the individual experience and } \\
\text { sayne, Davies \& Adams }\end{array}$ \\
$\begin{array}{l}\text { "The totality with a physical and a socio-cultural context" } \\
\text { on the relationship between individual's or society's perception } \\
\text { of, understanding of and interaction with the sonic } \\
\text { environment" }\end{array}$
\end{tabular}

Brown, Kang \& Gjestland "Soundscape exists through human perception of the acoustic (2011, p. 388) environment of a place ... the soundscape term has also been used to describe the physical environment before perception"

Pijanowski et al. (2011, "The collection of biological, geophysical and anthropogenic p. 1214) sounds that emanate from a landscape and which vary over space and time reflecting important ecosystem processes and human activities"

Truax (2012, p. 2) "An environment of sound (whether acoustic or electroacoustic) with an emphasis on how it is perceived by listeners"

Brown (2013, p. 96) "The way the acoustic environment is perceived and understood by the individual, or by a society"

"Acoustic environment of a place ... all the sounds in a place that are present, and 'available', to a user of the place to hear"

Davies et al. (2013, p. "Complete sound environment in a location and the human 224) response to it"

Smith \& Pijanowski "The perception of all sounds ... emanating from a given (2014, p. 65) landscape"

Generally, the study of soundscape comprises three main elements and their interconnections: namely sound (sonic properties), people (experience, perception) and place (landscape, environmental conditions, sociocultural context) (Çamci \& Erkan, 2012-2013; Wrightson, 2000, p. 12; Zhang \& Kang, 2007, p. 76). The types of soundscape studies, according to purpose, include soundscape documentation, description, management and creation.

\section{Soundscape Documentation}

Documentation of soundscape leads to archiving of cultural heritage sounds that may be facing irreversible loss in the near future due to environmental or cultural change. A natural soundscape has a diverse biophony and geophony whilst an urban space usually has a reduced variety of natural sound profiles with anthropophony and electrophony dominating 
the soundscape. Documentation of soundscapes is usually the initial stage to soundscape description and management that can be a useful reference to soundscape creation.

For example, Huang and Kang (2015) presented a description of sound sources, SPL and frequency distribution of Lhasa-a UNESCO World Heritage Site-and made comparisons with other historic centres. Apart from this, the Environmental Agency in Japan conducted the "100 Soundscapes of Japan: Preserving Our Heritage" project in 1994-1997 where a hundred soundscapes that contained the natural and cultural meanings of the country were recorded and conserved. In 2011, a mega earthquake caused a tsunami and a nuclear plant accident which affected some of the study sites. Data from this project managed to provide information for a comparative study on the changes of the soundscape carried out by the Soundscape Association of Japan (SAJ) under the project "Soundscape Projects for Earthquake Disaster 311" (Nagahata, 2012-2013).

\section{Soundscape Description}

Soundscape description involves analysing, interpreting and evaluation that usually includes detailed observations of sounds and their properties. This process encourages appreciation and understanding of sounds in a place. The findings on sonic properties and sound experiences can lead to deeper understandings of semantics and sonic potentials as well as satisfaction and sound preferences among the users of a place.

Subsequently, the outcomes of describing and evaluating soundscape can be a relevant source for soundscape monitoring and design. As stated by Schafer (1977/1994) "sound romances and sound phobias, would not only be of inestimable value in a consideration of sound symbolism, but could obviously give valuable directives for future soundscape design" (p. 146). By identifying sounds that are culturally meaningful and preferable as well as sounds that are perceived as intrusive and detrimental, soundscape evaluation can be used as a reference to improve soundscapes such as by introducing the types of sound sources to a place with certain acoustical quality within the acceptable range of loudness and sharpness; and masking of unwanted sounds using pleasant sounds. For example, research showed that preferred sounds in urban areas were natural sounds such as water from fountains and birds chirping (Zhang \& Kang, 2007), and "culturally approved sounds, such as church bells, music on the street, and bells and music from a clock" (Zhang \& Kang, 2007, p. 71). The temporal condition of sound was found to be significant such as the varied flow rate-instead of constant sounds - of the water fountain in an urban square was found to be more attractive (Zhang \& Kang, 2007, p. 79). These sounds can be introduced in urban cities to enhance sound environments.

\section{Soundscape Management}

Soundscape management involves two main components: firstly, noise abatement to reduce annoying or harmful sounds, and secondly, the introduction of positive sounds. Soundscape study identifies "noise" that can cause physical impairment to our ears and other health issues:

Beyond the risks to hearing, noise exposure can result in various forms of stress on the body, including interference with sleep rhythms, as well as task performance, effects that should be 
of concern even to young people who are often subject to other forms of stress. (Truax, 2012, p. 4)

Cain, Jennings and Poxon (2013) stated that "The emphasis is now on 'positive' soundscapes. Simply removing negative sounds, however, is not enough-if negative sounds are not replaced by more positive ones the soundscape can become less negative but not necessarily more positive" (p. 232). Similarly, Raimbault and Dubois (2005) stated the difference between "experts in noise" who merely curb noise pollution and "city-users and planners" who design or frequently use a place, that:

Experts in noise control led to an urban soundscape becoming less negative (less unpleasant) without being more positive (pleasant) whereas city-users and planners' assessments of urban soundscapes show that the quality of soundscapes refers to the question of quality of life, way of life and activities. (p. 346)

A positive soundscape contains meaningful sounds, facilitates activities with functional sounds, and leads to acoustic comfort and physical health (Brown, Kang \& Gjestland, 2011; Smith \& Pijanowski, 2014). For example, introducing water sounds can improve urban soundscape by masking traffic noise (Jeon et al., 2012).

\section{Soundscape Creation}

Acoustic design is an addition to the typical way of merely physically designing a space. It has been increasingly significant in the development of an area or the construction of a building. Sonic environments can affect landscape values (Carles, Barrio \& de Lucio, 1999). For example, the property values in North America were found to decrease by $0.5-0.9 \%$ with every increase of decibel (Nelson, 2004). Another study found that "[housing] plots located in the zone with noise exceedance at night were about $57 \%$ cheaper than those located outside this zone" (Łowicki \& Piotrowska, 2015). Architectural design can affect how sounds diffuse across an area as well as influence how people use a place. Specific artistic, cultural or psychologically restorative sound characteristics can be incorporated into soundscape design to establish an identity that delivers sociocultural meanings and enhance the functions of a place.

\section{Methods In Soundscape Study}

As soundscape study places emphasis on perception, most of the methods that have been used in investigations are listener-based. Methods in soundscape study usually involve audio recording; soundwalk; and questionnaire, interview and/or focus group. Participantobservation is also useful, especially for the qualitative approach. Some studies generate sound maps to visualise the soundscape properties of a place with its architectural features. Experiments have also been conducted in laboratories mostly for soundscape assessment. Soundscape research usually uses methods triangulation that involves sound analysis, questionnaire and interview to cross-check data for convergence and corroboration.

\section{Audio Recording and Sound Measurement}

Contextual and phenomenological binaural audio recording is one of the methods to document the sound profiles in an environment. Recordings usually include all sounds that are present in the acoustic space of the soundscape including featured and background 
sounds as well as natural and human sounds. Schafer (2012-2013) explained that "phenomenological recording is not to interfere with the sounds around you. It differs from focused recording where one tries to eliminate interference from surrounding sounds" (p. 8). Phenomenological recordings include the total sound environment as it is experienced in person, for example, the sounds from the forest at a music event in a village, or the sounds of the crowd at a music festival. Andrisani (2011) identified two types of audio documentation: "fixed spatial perspective" is captured at only one particular location whereas "moving spatial perspective" is obtained by moving from one place to another to document the transitional sounds between locations (p. 32).

Audio recording is able to capture the sounds and their physical properties objectively without human preference and personal hearing selection. Frequency spectrograms from audio recordings can be used to assist in identifying sound sources, their physical characteristics as well as being used as a symbolic notation for references. Acoustic studies of soundscape may include analysis of parameters such as sharpness, roughness, fluctuation strength, tonality and loudness (Yang \& Kang, 2013; Zhang \& Kang, 2007).

Field measurements of Sound Pressure Level (SPL) can be carried out using a sound level meter to obtain readings such as Leq (Equivalent Continuous Sound Level), Lmax (maximum sound level), Lmin (minimum sound level), L50 and L10. For the setting of "slow" response time, A-weighted measurement and exchange rate of $3 \mathrm{~dB}$ or $5 \mathrm{~dB}$ is used. Some studies employ simultaneous audio recording of soundscape and in situ measurements of SPL with a questionnaire to obtain situated soundscape perception from participants. Reverberation measurement can be made by "burst[ing] a balloon or to use a pistol to generate an impulse, and at the same time to record the process of sound decay" (Zhang \& Kang, 2007, p. 70).

Sound map is a visual representation of the geography of a place with information on sounds (Huang \& Kang, 2015). It is created to provide an overview of the sound distribution across a landscape. Kang (2007) explained that the use of the sound map is:

To visualise and assess the acoustic environment. ... [To] give an accurate statement of noise levels in a specific location, provide noise trend data, establish exposure levels of a population for risk estimation purposes, identify pollution hotspots or quiet areas, yield information as to the effectiveness of noise management schemes, and indicate management/legislative/policy changes that may be required. (p. 154)

There are three types of maps, namely noise map, sound map and soundscape map (Aletta \& Kang, 2015). A noise map is a depiction of acoustic properties such as sound levels which is commonly used to chart the distribution of unwanted sounds such as traffic noise. A sound map portrays the types of sounds that exist in a place such as a water fountain, background music or natural sounds. A soundscape map is a perceptual illustration of a users' sonic experience. Software such as CadnaA, ENM, Fluidyn, GIpSynoise, IMMI, LIMA, Mithra, Noisemap, Predictor, SoundPLAN can be used to generate these maps (Kang, 2007, p. 152).

\section{Soundwalk}

Listening is considered a significant and integral component in soundscape studies because the evaluation of soundscape is closely related to users' perception: "Soundwalks capture participant response to a real environment at the time of exposure" (Bruce \& Davies, 2014, 
p. 2). Thus, soundwalk is a method that is widely used in soundscape study along with a questionnaire or interview on sonic experience. The procedure of soundwalk is to walk around a place, listening to the sonic environment and giving comments (for more information on soundwalk method in soundscape research, refer to Berglund, Eriksen \& Nilsson, 2001 [with 69 residents listening to 6 places]; Bruce \& Davies, 2014; Davies et al., 2013; Kang \& Zhang, 2010 [48 people in urban open public space]; Liu et al., 2014; Southworth, 1969; Zhang \& Kang, 2007 [approximately 500 participants in 4 urban open spaces]).

\section{Questionnaire, Interview and Focus Group}

Questionnaires, interviews or focus groups are usually used to collect data on phenomenological sonic experiences. These methods are employed mainly to understand the perceptions of a built environment for the evaluation and design of a sound environment that is fit for its users. The type of questions can be the psychoacoustics, semantics and aesthetic perceptions of sounds (Schafer, 1977/1994, pp. 148-150) which may include the evaluation of sound levels, identification of sound sources, types of wanted and unwanted sounds and suggestions for improvement. A sample size of about 100 to 150 is usually acceptable for the evaluation of soundscape in urban open public spaces (Kang \& Zhang, 2010, p. 156). For questionnaire design, Kang (2007) suggested that:

The questionnaire was not introduced as a soundscape survey, but as an enquiry relating to general environmental conditions including thermal, lighting, wind, humidity and visual environment. Such an integrative consideration of various factors is useful for avoiding any possibility of bias towards the acoustic aspect. The interviewees were the users, not passersby, of the squares, and were selected randomly. (p. 56)

Semantic differential analysis (Osgood, Suci \& Tannenbaum, 1957) has been commonly employed in a soundscape questionnaire by quantifying perception. The semantic differential technique uses pairs of opposite dimensions (e.g., quiet-noisy, dislike-like, uncomfortablecomfortable and unpleasant-pleasant) with five, seven or ten points in the bipolar rating scales (for more information on semantic differential analysis method in soundscape research, refer to Davies et al., 2013; Cain, Jennings \& Poxon, 2013; Kang, 2007; Kang \& Zhang, 2010).

\section{Different Fields Of Soundscape Study}

The sonic environment is acknowledged as a significant resource capable of transmitting meanings and revealing sociocultural conditions as well as affecting work efficiency and health. Since the 1960s, scholarly studies on soundscape have increased with multiple perspectives such as cultural studies, soundscape design, aural health and global environmental concerns. The study of soundscape is dynamically evolving and the following section briefly describes some of the different fields.

Soundscape study encompasses several terminologies and paradigms. The pioneering studies by Southworth and Schafer, acoustemology, music ecology and soundscape engineering have been influential in varying degrees to the current methods. The focus of study can be on the physical characteristics of sounds; the context of sounds; the meaning, effects and functions of sounds; soundscape perception; soundscape quality; soundscape management and design; 
soundscape archiving; and soundscape composition. The concern of soundscape study can either be ecological, interpretative, phenomenological, health (aural, physical and psychological health), artistic, pragmatic or from the activism viewpoints. Table 2 shows a summary and emphasis on some of the different types of soundscape studies. These different types of studies may share similarities.

Table 2

Different types of soundscape studies.

\begin{tabular}{|c|c|}
\hline Type & Emphasis \\
\hline acoustic ecology & humanities approach to societal and environmental concerns \\
\hline acoustemology & sounds as a medium to understand place and culture \\
\hline $\begin{array}{l}\text { music } \\
\text { ecomusicology }\end{array}$ & interconnections between music and environment \\
\hline acoustics engineering & $\begin{array}{l}\text { management and design of a space and sounds to create a } \\
\text { positive soundscape }\end{array}$ \\
\hline artistic creativity & $\begin{array}{l}\text { artistic and creative expressions through soundscape } \\
\text { composition and sound installation }\end{array}$ \\
\hline wellbeing & $\begin{array}{l}\text { promoting physiological and psychological health through } \\
\text { reduced exposure to harmful sounds and/or experience of } \\
\text { positive soundscape }\end{array}$ \\
\hline soundscape ecology & networking in a socio-ecosystem within a landscape \\
\hline $\begin{array}{l}\text { bioacoustics, biomusic, } \\
\text { zoomusicology }\end{array}$ & $\begin{array}{l}\text { documentation, understanding and conservation of natural } \\
\text { sounds }\end{array}$ \\
\hline
\end{tabular}

\section{Early Studies}

One of the earliest soundscape studies was by Southworth (1969) who carried out a research in Boston City, USA to explore varied sonic perceptions and the way sounds influenced visual observations. The research was carried out via three different sample groups who travelled around several places in the city, namely a group with only visual exposure (wearing earplugs and earmuffs), a second group with only auditory exposure (blindfolded) and the third one with visual-auditory exposure. His study highlighted the informativeness of sounds as well as the close interaction between visual and auditory perceptions. As he specialised in city planning, he also suggested possible ways of sonic design in open and acoustically responsive spaces to enhance the experience in a place. Although the report was comparatively brief, the objectives, methods and findings of the study could be seen in similar or expansive forms in numerous ensuing soundscape studies.

\section{Acoustic Ecology}

A prominent project led by R. Murray Schafer in the late 1960s at the Sonic Research Studio of the School of Communication, Simon Fraser University, Canada was on a comparative study of different world soundscapes. In 1971, the "World Soundscape Project" was formed and the types of research included sound perception, sound pollution and soundscape design. In 1977, an influential book was published by Schafer entitled The Soundscape: Our Sonic Environment and The Tuning of the World. It presented elaborated descriptions of past natural soundscapes, the relationships between music and soundscapes in several historical events and descriptions of the sounds of modernity. Besides drawing attention to the significance of the sonic environment, Schafer expressed concerns about the adverse effects 
of the modern soundscape and the declining competency in listening. Subsequently, this brought about an activist call to analyse and improve the quality of soundscapes.

Schafer introduced the term "acoustic ecology" which generally means the effects of soundscape on life and society (Schafer, 1977/1994; Wrightson, 2000). Truax (2012) defined "acoustic ecology" as a "system of relationships between organisms and their sonic environments with particular emphasis on a functional balance or an attention to dysfunctional behaviour" (p. 2). In 1993, the World Forum for Acoustic Ecology (WFAE) was established and it continues the focus of previous soundscape studies on listening modality, conserving natural soundscapes and soundscape design (wfae.proscenia.net). Since 2000, studies on acoustic ecology have been disseminated through the newsletter "WFAE News Quarterly" and the biannual publication of Soundscape: The Journal of Acoustic Ecology. At present, WFAE has several affiliated organisations such as the Soundscape Association of Japan (SAJ) (1993), Forum für Klanglandschaft (FKL) (1995), Canadian Association for Sound Ecology (CASE) (1996), Australian Forum for Acoustic Ecology (AFAE) (1998), The United Kingdom and Ireland Soundscape Community (UKISC) (1999) and American Society for Acoustic Ecology (ASAE) (2006).

\section{Acoustemology}

A descriptive and interpretative approach to soundscape through in-depth ethnographic studies focusing on music culture was carried out by Steven Feld. Feld started his research at the Bosavi region of Papua New Guinea in the 1970s-1980s with an anthropology and ethnomusicology background. During the 1990s, his research highlighted the relation between music and the sonic environment. From the sound worlds of the Kaluli people and attributing his thoughts to Schafer's remark that "man echoes the soundscape in speech and music" (1977/1994, p. 40), Feld developed a related branch of the soundscape: "echo-museecology" and this was later termed as "acoustemology" (acoustic epistemology) (Feld, 1994, 1996). "Acoustemology" means sounds as the principal medium for knowing and experiencing a place:

An exploration of sonic sensibilities, specifically of ways in which sound is central to making sense, to knowing, to experiential truth. ... as a sensual space-time, the experience of place potentially can always be grounded in an acoustic dimension. This is so because space indexed the distribution of sounds, and time indexes the motion of sounds. (Feld, 1996, p. 97)

\section{Music Ecology and Ecomusicology}

Another area of soundscape study with its focus on music is termed as music ecology or ecomusicology. Harley (1996) described music ecology as the study of music in relation to other sonic elements in the soundscape-regardless of whether they are natural, anthropological or electro-mechanical-and the environment.

A similar term, "ecomusicology" has been increasingly used among music scholars with the establishment of the Ecocriticism Study Group (ESG) by the American Musicological Society (AMS) in 2007 and later the Ecomusicology Special Interest Group (ESIG) by the Society for Ethnomusicology (SEM) in 2011 (www.ecomusicology.info; www.ams-esg.org). Allen, the chair of ESG, defined ecomusicology as "how art reflects, relates to, or relies on nature" (2011, p. 391) and "a socially engaged musicology that seeks to understand not just music, musicians, 
and/or musical communities, but also their interconnections in the world, both natural and socially constructed" (2011, p. 393). He described ecomusicology as "ecocritical musicology" - rather than "ecological musicology" - meaning a study of the products of music culture from the viewpoint of human-environment relationships (2011, p. 393). The theme revolves around the relationship between music, culture and nature; the connection of music, place and society; the influence of environments on music; and music sustainability (Allen, 2011; Pedelty, 2012).

One example is an anthropological research carried out by Rudge (2019) among an indigenous community in Malaysia where bird sounds in their living environment are musically reproduced. Besides, a research conducted by Chieng (2019) explained the sociocultural meaning of world music in an international festival in relation to the time and place of the soundscape experience.

\section{Acoustic Engineering of Soundscape}

Soundscape in the field of acoustic engineering emphasises soundscape evaluation, management and design. The setting of this type of study focuses on the anthropological space of built or mixed environments such as a public square, park, residential area or shopping mall. Such studies are usually applicable for the improvement of soundscape quality and acoustic comfort "to enhance, enable, or facilitate human enjoyment, health, well-being or activity" (Brown, Kang \& Gjestland, 2011, p. 391).

Studies in urban open spaces had found that overall sound levels that were above 65-70 dBA would cause annoyance and efforts to reduce the sound level were more necessary than examining the types of sound present (Zhang \& Kang, 2007). However, merely reducing sound levels might not improve the acoustic comfort as quietness or silence was not always considered as a positive soundscape (Brown, 2013, pp. 99-100; Kang, 2007). On the other hand, in a space with overall sound levels that were below 65-70 dBA, the type of sound sources played an important role in the evaluation of acoustic comfort depending on the users' characteristics (Zhang \& Kang, 2007, pp. 68, 78). Different places would require different types of soundscapes, for example, a peaceful atmosphere with natural sounds for a park compared to a vibrant soundscape for a shopping mall.

Thus, apart from noise abatement, soundscape design also involves introducing sounds to a place by evaluating its architectural design with its physics of reverberation and sound propagation as well as examining the functions of the place. The sound introduced to a place may be used as masking so that it results in "one sound interfering with the perception of another sound" (Goelzer, Hansen \& Sehrndt, 2001, p. 43), or to add pleasantness to the environment.

\section{Soundscape and Artistic Creativity}

The term "soundscape" has also been used in sonic arts and installation for the artistic creation of a sonic environment. Soundscape composition began at Simon Fraser University in the early 1970s (Truax, 2002). The significant soundscape works by the notable composer Hildegard Westerkamp were documented in detail by McCartney (1999) in a doctoral thesis. Other examples are the writings by Weidenaar (2002) and Hahn (2002) who integrated the soundscapes of Zagreb and Jones Street respectively into their compositions. In the article, 
Weidennar (2002) emphasised the details of digital processing and compositional techniques in multimedia production. Hahn (2002) attempted to use personal sound experiences in Zagreb into the composition to communicate the image of Croatia to the outside world against the "barbaric Balkans" impression disseminated by the Western media. Besides, there were soundscape compositions based on references to archaeological and historical resources created as acoustic representations of the past for the play Bermulanya Di Sini...Kedah Tua [Kedah Tua...Where It All Began]" (Manoharan \& Othman, 2019).

\section{Soundscape and Well Being}

The physiological and psychological health effects of the sound environment have been a concern. Studies showed that noise is associated with increased cardiovascular risk (Begou, Kassomenos \& Kelessis, 2020). Sound art, apart from being a form of creative expression, can potentially act as a therapy for people with dementia where the broadcast of nature and acoustic instrument soundscapes resulted in comfort and positive physical reactions (Kamal et al., 2018). Furthermore, playback of everyday sounds can stimulate emotional responses and conversations among people with dementia (Campbell et al., 2019).

Research on soundscape in living spaces are increasingly available (Lewis, 2019; Meng et al., 2020). In Malaysia, the levels of traffic noise in residential areas were found to be exceeding the permissible limits (Herni et al., 2019). Domestic noise "reduces productivity and impairs cognitive function" (Dean, 2019); creates tension among neighbours (Kerr, Gibson \& Klocker, 2018); causes adverse health effects (Maschke \& Niemann, 2007; Ottoz, Rizzi \& Nastasi, 2018); as well as leads to violence and abuse where "a 1-dB rise in noise levels increases the assault rate by 2.6\%" (Heer, 2019). As Industrial Revolution 4.0 and digital disruption in education have led to the revolutionary way of Work From Home (WFH) and Home-Based Learning ( $\mathrm{HBL})$, more evidence-based research and guidelines on residential soundscape management are becoming necessary to create a pleasant and functional environment conducive to remote working and learning at home.

\section{Soundscape Ecology}

"Soundscape ecology" investigates the connections between sounds and landscape in terms of how sounds reflect the ecosystem and the consequences of human activities in a particular physical and spatial condition (Itm.agriculture.purdue.edu; Pijanowski et al., 2011).

Recently, artificial intelligence has been experimented upon to monitor the soundscape (Green \& Murphy, 2020). In Sabah, Malaysia, the SAFE (Stability of Altered Forest Environment) Acoustics Project employs machine learning to monitor ecosystem health by placing microphones in the rainforest and using "acoustic fingerprints" to identify biodiversity and machinery sounds of chainsaws or gunshots (Sethi et al., 2020; https://www.safeproject.net/).

\section{Bioacoustics, Biomusic and Zoomusicology}

Other tangential fields of soundscape studies include bioacoustics, biomusic and zoomusicology that examine non-human sound worlds such as mechanisms in biological sound production and sound communications (Krause, 1998; Martinelli, 2008; Sorce Keller, 2012). 


\section{Soundscape Studies Based on The Type of Space}

In addition to the focus of study, soundscape research is usually carried out in close relationship to a place to interpret the experience of being in a place or to enhance the function of the soundscape of an area. Research has been carried out in different physical environments which include natural environments, villages or cities; different types of space shape (e.g., long space of underground train tunnel); a place with a specific function (e.g., urban park, shopping mall); and with specific sound events (e.g., music festival, water fountain). On another note, related to acousmatic music, Smalley (2007) conceptualised "perspectival space" from the listener's observation point and delineated the characteristics of "source-bonded", "enacted" and "spectral" spaces. Some examples of research based on the physical types of space are presented below.

\section{Natural Environment}

Documenting natural sounds is either the sound collection of a certain species recorded in its environment or a general natural soundscape of a place. Some examples of a soundscape library of species sounds and/or natural soundscapes are: Western Soundscape Archive (www.westernsoundscape.org), Macaulay Library (macaulaylibrary.org), Museum Für Naturkunde (Museum of Natural History) (www.tierstimmenarchiv.de), The California Library of Natural Sounds (www.naturesounds.org), and Xeno-canto (bird sounds) (www.xenocanto.org). Bernie Krause, a bio-acoustician and the founder of "Wild Sanctuary" has been recording both marine and terrestrial soundscapes since the late 1960s (www.wildsanctuary.com). Loufopoulos and Mniestris (2011) also recorded soundscapes of a protected area on the Greek island of Corfu in 2006-2007. Natural or heritage sound samples taken from the environment are used as sources for comparative studies; archival materials for the preservation or conservation especially of those that are vulnerable to extinction; museological items (Zisiou, 2011); and/or resources for electroacoustic compositions or sound sculpture installations either for soundscape design or audio art (Truax, 2012).

\section{Built Environment}

Built environment refers to "humans' manufactured world of dwellings, buildings, infrastructure, constructed landscapes and urban social spaces" (Allen, 2011, p. 392). Soundscape research that had been carried out in built environments mostly aimed to reduce noise annoyance; improve the functionality of the soundscape and acoustic comfort among users; and maintain or introduce meaningful sounds to the environment.

One example of soundscape research at historical sites was that done by Escobar et al. (2012) who carried out noise measurements and sociological studies on the sound perception of a UNESCO World Heritage Site at Cáceres, Spain. They identified that the site could be considered quite due to the design of the building that restricted vehicle access.

For studies based on the types of built environment, there were detailed studies focus on man-made natural environments such as national or city parks (Liu et al., 2014; Szeremeta \& Zannin, 2009) as well as public open spaces (Bruce \& Davies, 2014; Escobar et al., 2012; Kang \& Zhang, 2010; Yang \& Kang, 2013). There were also studies on indoor soundscape, for example, shopping malls (Bruce \& Davies, 2014; Hynes \& Manson, 2016; Meng, Kang \& Jin, 2013); learning institutions in Malaysia (Samsuri et al., 2019), dining spaces (Lindborg, 2015); 
critical care unit (Zainah et al., 2020); hospital (Oleksy \& Schlesinger, 2019) and nursing homes (Thomas et al., 2020).

Kang (2007) presented a detailed study of the soundscapes in two urban open public spaces over four seasons from the summer of 2001 in each of seven European cities. Zhang and Kang (2007) also presented surveys and field recordings in 19 open public spaces that included residential, cultural and tourism places, a railway station and multifunctional squares in Sheffield, Beijing, Alimos, Thessaloniki, Sesto San Giovanni, Cambridge, Kassel and Fribourg. Soundscape analysis in urban open public spaces in Sheffield, United Kingdom was also carried out on the correlation between perceived and measured sound levels, soundscape preference and correlation with demographic variables (Kang \& Zhang, 2010). Besides this, the perception of low frequency in urban areas had been studied in three French cities (Guastavino et al., 2001).

In the context of urban or modernised spaces, Schafer (1977/1994) discussed the soundscapes during the Industrial Revolution and the Electric Revolution and how these movements led to the emergence of new soundscapes with a reduction of diversity in sound sources. For the soundscape of villages or cities, the World Soundscape Project (WSP) carried out several major projects to document soundscapes. Firstly, "The Vancouver Soundscape 1973 " is a CD publication with edited sound clips of Vancouver in 1972-1973 and 1980-1981. After more than two decades, the sequel "Soundscape Vancouver 1996" was produced and it includes a documentary of the changing soundscape. In 1974, "Soundscapes of Canada" was introduced through the media; it is a series of one-hour radio programmes broadcasting recorded sonic environments of Canada and music compositions using Canadian soundscapes. In a 1975 project, a comparison of five villages, one each in Sweden, Germany, Italy, France and Scotland resulted in the publication of "Five Village Soundscapes" (Schafer, 1977) and these places were revisited in 2000-2004 by the team of the project "Finnish Acoustic Environments in Change" during which comparative studies were carried out (Järviluoma et al., 2009).

Besides this, the Human-Environment Modelling and Analysis (HEMA) by the Department of Forestry and Natural Resources at Purdue University documented the soundscapes of three places in Indiana (2008), Costa Rica (2008) and Wisconsin (2012) (Itm.agriculture.purdue.edu). HEMA also developed "Pumilio" which is a web-based public system to manage and archive soundscape recordings by plotting the sounds on a geographical map (Villanueva-Rivera \& Pijanowski, 2012).

Furthermore, Moore (2013) described the tourism-heightened island of Bali in terms of its urbanised, religious, cultural and musical sounds implicit in the diverse and multi-channelled influences on the city soundscapes. Oosterbaan (2009) made an argument that the soundscape created by broadcasting via electronic media to the public in a favela in Rio de Janeiro managed to create territories and assert the beliefs of certain parties.

\section{Conclusion}

The invisible sonic environment has been recognised as an interdependent dimension to the physical-visual environment and as a resource that relates to the multiple facets of living. Soundscape studies have been conducted from different specialisations and mostly in 
interdisciplinary ways. The availability of technological equipment and computational software in recent decades has increased the feasibility of carrying out soundscape research.

Soundscape studies include natural environments in the documentation of terrestrial or oceanic non-human sounds either for the purpose of archiving or to be used as a resource for sonic arts. Apart from biological sounds, collecting historical and cultural soundscapes that can be lost irrevocably due to industrialisation is an act of historical preservation of the inherent values of the sound environment. In built environments, research projects on the soundscapes in urban open spaces, parks, shopping malls, hospitals, eatery places and residences have been increasing from the civil, architectural or engineering approaches to increase acoustic comfort and to enhance the experience of users.

Although documentations of different soundscapes are plentiful and increasing in numbers, there are still much that can be recorded and examined from the viewpoint that there are diverse contexts and aspects of soundscape research. Based on the available sources for reference, soundscape research sites in Asian countries are currently limited in availability. Soundscape studies began to gain popularity in Asian countries in 2011, around six years later when compared to the other parts of the world (To et al., 2018). A review of publications over the past four decades showed that the United States produced 571 publications whilst the United Kingdom 519 whereas the total publications of 11 countries in Southeast Asia were only 149 (To et al., 2018). In another review of 1,309 papers on soundscape, only $18 \%$ of the studies were conducted in tropical areas as compared to $56 \%$ on temperate regions (Scarpelli et al., 2020).

This narrative review attempts to provide a preliminary referential point for new soundscape researchers and for the expansion of soundscape studies globally on diverse ecosystems, sonic components and meanings due to differences in climate, biodiversity and culture. Further investigations can be done on anthropological soundscapes that depict the sociocultural condition of a place. Soundscape research can also be conducted from the aspect of specific and temporal events such as music festivals or exhibitions. Besides this, most of the soundscapes have been documented as sound objects whereas the context and meanings of sound yearn for more detailed investigations. Further in-depth studies of soundscape will contribute findings on its different evolving areas as well as to the development of research methodologies and frameworks. After 50 years since its outset in scholarly academic research, many types of new soundscape research are developing among various disciplines in different regions that will very soon necessitate another literature review focusing on such studies.

\section{Acknowledgment}

This paper is based on a segment of a research project funded by the Putra Grant of Universiti Putra Malaysia (Project No.: GP-IPS/2016/9473600). 


\section{References}

Aletta, F., \& Kang, J. (2015). Soundscape approach integrating noise mapping techniques: A case study in Brighton, UK. Noise Mapping, 2(1), 1-12. https://doi.org/10.1515/noise2015-0001

Allen, A. S. (2011). Ecomusicology: Ecocriticism and musicology. Journal of the American Musicological Society, 64(2), 391-394. https://doi.org/10.1525/jams.2011.64.2.391

Andrisani, V. (2011). Revisiting the Vancouver soundscape tape collection: Motives, intentions \& practice. Soundscape: The Journal of Acoustic Ecology, 11(1), 28-32. https://www.wfae.net/uploads/5/9/8/4/59849633/soundscape_volume11.pdf

Begou, P., Kassomenos, P., \& Kelessis A. (2020). Effects of road traffic noise on the prevalence of cardiovascular diseases: The case of Thessaloniki, Greece. Science of the Total Environment, 703, 134477-134486. https://doi.org/10.1016/j.scitotenv.2019.134477

Berglund, B., Eriksen, C. A., \& Nilsson, M. E. (2001). Perceptual characterization of soundscapes in residential areas. Proceedings of the 17th International Conference on Acoustics, Rome, Italy (pp. 6-7).

http://www.icacommission.org/proceedings/ica2001rome/6_14.pdf

Brown, A. L. (2013). The sounds people might hear in a place? Describing sources in the acoustic environment, and their role in the perception of soundscape. In J. Kang, K. Chourmouziadou, K. Sakantamis, B. Wang, B., \& Y. Hao (Eds.), Soundscape of European cities and landscapes (pp. 96-100). Soundscape-COST.

Brown, A. L., Kang, J., \& Gjestland, T. (2011). Towards standardization in soundscape preference assessment. Applied Acoustics, 72, 387-392.

https://doi.org/10.1016/j.apacoust.2011.01.001

Bruce, N. S., \& Davies, W. J. (2014). The effects of expectation on the perception of soundscapes. Applied Acoustics, 85, 1-11.

https://doi.org/10.1016/j.apacoust.2014.03.016

Cain, R., Jennings, P., \& Poxon, J. (2013). The development and application of the emotional dimensions of a soundscape. Applied Acoustics, 74, 232-239. https://doi.org/10.1016/j.apacoust.2011.11.006

Çamci, A., \& Erkan, K. (2012-2013). Interferences between acoustic communication threads in enclosed social environments of Istanbul. Soundscape: The Journal of Acoustic Ecology, 12(1), 20-24. https://www.wfae.net/uploads/5/9/8/4/59849633/soundscape_volume12.pdf

Campbell, S., Frohlich, D., Alm, N., \& Vaughan, A. (2019). Sentimental audio memories: Exploring the emotion and meaning of everyday sounds. Proceedings of 4th Dementia Lab Conference, 1117, 73-81. https://doi.org/10.1007/978-3-030-33540-3_7

Carles, J. L., Barrio, I. L., \& de Lucio, J. V. (1999). Sound influence on landscape values. Landscape and Urban Planning, 43(4), 191-200. https://doi.org/10.1016/S01692046(98)00112-1

Chieng, J. (2019). Sound properties, festival experience and soundscape perception of the Rainforest World Music Festival in Sarawak Cultural Village, Malaysia [Doctoral thesis, The University of Sheffield, United Kingdom]. White Rose eTheses Online. http://etheses.whiterose.ac.uk/23432/

Davies, W. J., Adams, M. D., Bruce, N. S., Cain, R., Carlyle, A., Cusack, P., Hall, D. A., Hume, K. I., Irwin, A., Jennings, P., Marselle, M., Plack, C. J., \& Poxon, J. (2013). Perception of soundscapes: An interdisciplinary approach. Applied Acoustics, 74(2), 224-231. https://doi.org/10.1016/j.apacoust.2012.05.010 
Dean, J. T. (2019). Noise, cognitive function, and worker productivity. https://joshuatdean.com/wpcontent/uploads/2019/01/NoiseCognitiveFunctionandWorkerProductivity.pdf

Escobar, V. G., Morillas, J. M. B., Gozalo, G. R., Vaquero, J. M., Sierra, J. A. M., Vílchez-Gómez, R., \& del Río, F. J. C. (2012). Acoustical environment of the medieval centre of Cáceres (Spain). Applied Acoustics, 73, 673-685. https://doi.org/10.1016/j.apacoust.2012.01.006

Feld, S. (1994). From ethnomusicology to echo-muse-ecology. The Soundscape Newsletter, 8, 9-13. http://ecoear.proscenia.net/wfaelibrary/library/newsletter/SNL8.PDF

Feld, S. (1996). Waterfalls of song: An acoustemology of place resounding in Bosavi, Papua New Guinea. In S. Feld, \& K. H. Basso (Eds.), Senses of place (pp. 91-135). School of American Research Press.

Goelzer, B., Hansen, C. H., \& Sehrndt, G. A. (2001). Occupational exposure to noise: Evaluation, prevention and control. Federal Institute for Occupational Health and Safety \& World Health Organization.

http://www.who.int/occupational_health/publications/noise.pdf?ua=1

Green, M., \& Murphy, D. (2020). Environmental sound monitoring using machine learning on mobile devices. Applied Acoustics, 159, 107041-107048. https://doi.org/10.1016/j.apacoust.2019.107041

Guastavino, C., Dubois, D., Polack, J., \& Arras, C. (2001). Low frequency perception in urban soundscapes: A cognitive approach. Proceedings of the 17th International Conference on Acoustics (pp. 34-35).

http://www.icacommission.org/proceedings/ica2001rome/8_10.pdf

Hahn, D. (2002). Creating the soundscape for "Zagreb Everywhere". Organised Sound, 7(1), 57-63. https://doi.org/10.1017/S1355771802001097

Harley, M. A. (1996). Notes on music ecology: As a new research paradigm. http://wfae.proscenia.net/library/articles/harly_paradigm.pdf

Heer, T. (2019). Noise pollution and violence. Grantham Research Institute on Climate Change and the Environment. The London School of Economics and Political Science. http://www.Ise.ac.uk/GranthamInstitute/event/noise-pollution-and-violence-timohener/

Herni, H., Nur Fatin N. H., Mohamad F. M. Y., Nur Atiqah M. N., Nur Hanani F. M. H., Nur Sabahiah A. S., Noorhazlinda A. R., Zaiton H., \& Faridah W. (2019). Road traffic noise levels at different types of residential areas in Nibong Tebal, Penang. International Journal of Integrated Engineering, 11(1), 101-112.

https://doi.org/10.30880/ijie.2019.11.01.013

Huang, L., \& Kang, J. (2015). The sound environment and soundscape preservation in historic city centres: The case study of Lhasa. Environment and Planning B: Planning and Design, 42(4), 652-674. https://doi.org/10.1068/b130073p

Hynes, N., \& Manson, S. (2016). The sound of silence: Why music in supermarkets is just a distraction. Journal of Retailing and Consumer Services, 28, 171-178. https://doi.org/10.1016/j.jretconser.2015.10.001

Järviluoma, H., Kytö, M., Truax, B., Uimonen, H., \& Vikman, N. (Eds.) (2009). Acoustic environments in change and five village soundscapes. TAMK University of Applied Sciences. 
Jeon, J. Y., Lee, P. J., You, J., \& Kang, J. (2012). Acoustical characteristics of water sounds for soundscape enhancement in urban open spaces. The Journal of the Acoustical Society of America, 131(3), 2101-2109. https://doi.org/10.1121/1.3681938

Kamal S., Norfadilah K., Ismail L., \& Norfarizah M. B. (2018). A study on applicability of sound art as therapy for Alzheimer's patients. Proceedings of the 4th Bandung Creative Movement International Conference on Creative Industries 2017 (pp. 5-9). https://doi.org/10.2991/bcm-17.2018.2

Kang, J. (2007). Urban sound environment. Taylor \& Francis.

Kang, J., \& Zhang, M. (2010). Semantic differential analysis of the soundscape in urban open public spaces. Building and Environment, 45(1), 150-157. https://doi.org/10.1016/j.buildenv.2009.05.014

Kerr, S. M., Gibson, C., \& Klocker, N. (2018). Parenting and neighbouring in the consolidating city: The emotional geographies of sound in apartments. Emotion, Space and Society, 26, 1-8. https://doi.org/10.1016/j.emospa.2017.11.002

Krause, B. L. (1998). Into a wild sanctuary: A life in music and natural sound. Heyday Books.

Lewis, C. (2019). Listening to community: The aural dimensions of neighbouring. The Sociological Review, 68, 94-109. https://doi.org/10.1177/0038026119853944

Lindborg, P. (2015). Psychoacoustic, physical, and perceptual features of restaurants: A field survey in Singapore. Applied Acoustics, 92, 47-60. https://doi.org/10.1016/j.apacoust.2015.01.002

Liu, J., Kang, J., Behm, H., \& Luo, T. (2014). Effects of landscape on soundscape perception: Soundwalks in city parks. Landscape and Urban Planning, 123, 30-40. https://doi.org/10.1016/j.landurbplan.2013.12.003

Loufopoulos, A., \& Mniestris, A. (2011). Soundscape models \& compositional strategies in acousmatic music. Soundscape: The Journal of Acoustic Ecology, 11(1), 33-36. https://www.wfae.net/uploads/5/9/8/4/59849633/soundscape_volume11.pdf

Łowicki, D., \& Piotrowska, S. (2015). Monetary valuation of road noise. Residential property prices as an indicator of the acoustic climate quality. Ecological Indicators, 52, 472-479. https://doi.org/10.1016/j.ecolind.2015.01.002

Manoharan, P., \& Othman, J. A. (2019). The soundscape of "Bermulanya Di Sini...Kedah Tua"!. Wacana Seni Journal of Arts Discourse, 18(Supp. 1), 33-38. https://doi.org/10.21315/ws2019.18.Supp.1.5.

Martinelli, D. (2008). Zoomusicology and musical universals: The question of processes. Trans: Revista Transcultural de Música, 12. https://www.sibetrans.com/trans/articulo/95/zoomusicology-and-musical-universalsthe-question-of-processes

Maschke, C., \& Niemann, H. (2007). Health effects of annoyance induced by neighbour noise. Noise Control Engineering Journal, 55(3), 348-356. https://doi.org/10.3397/1.2741308

McCartney, A. S. J. (1999). Sounding places: Situated conversations through the soundscape compositions of Hildegard Westerkamp (Doctoral thesis, York University, Ontario). https://hildegardwesterkamp.ca/resources/PDFs/writings-pdf/Andradiss.pdf

Meng, Q., Kang, J., \& Jin, H. (2013). Field study on the influence of spatial and environmental characteristics on the evaluation of subjective loudness and acoustic comfort in underground shopping streets. Applied Acoustics, 74(8), 1001-1009.

https://doi.org/10.1016/j.apacoust.2013.02.003 
Meng, Q., Zhang, J., Kang, J., \& Wu, Y. (2020). Effects of sound environment on the sleep of college students in China. Science of the Total Environment, 705, 135794-135815. https://doi.org/10.1016/j.scitotenv.2019.135794

Moore, R. E. (2013). A city cacophonous: Traversing Denpasar, Bali's disparate soundworlds. In Mohd Anis M. N., P. Matusky, Tan S. B., J. Pugh-Kitingan \& Felicidad P. (Eds.), Proceedings of the 2nd Symposium of the ICTM Study Group on Performing Arts of Southeast Asia (pp. 21-25). ICTM Study Group on Performing Arts of Southeast Asia.

Nagahata, K. (2012-2013). What should the soundscape community do when listening to the soundscapes of Fukushima? Soundscape: The Journal of Acoustic Ecology, 12(1), 15-19. https://www.wfae.net/uploads/5/9/8/4/59849633/soundscape_volume12.pdf

Nelson, J. P. (2004). Meta-analysis of airport noise and hedonic property values: Problems and prospects. Journal of Transport Economics and Policy, 38(1), 1-27. http://www.jstor.org/stable/20173043

Oleksy, A. J., \& Schlesinger, J. J. (2019). What's all that noise-Improving the hospital soundscape. Journal of Clinical Monitory and Computing, 33, 557-562. https://doi.org/10.1007/s10877-018-0215-3

Oosterbaan, M. (2009). Sonic supremacy: Sound, space and charisma in a Favela in Rio de Janeiro. Critique of Anthropology, 29(1), 81-104. https://doi.org/10.1177/0308275X08101028

Osgood, C. E., Suci, G. J., \& Tannenbaum, P. H. (1957). The measurement of meaning. University of Illinois Press.

Ottoz, E., Rizzi, L., \& Nastasi, F. (2018). Recreational noise: Impact and costs for annoyed residents in Milan and Turin. Applied Acoustics, 133, 173-181. https://doi.org/10.1016/j.apacoust.2017.12.021

Payne, R. S., Davies, W. J., \& Adams, M. D. (2009). Research into the practical and policy applications of soundscape concepts and techniques in urban areas (NANR 200). Department for Environment, Food and Rural Affairs, University of Salford. http://randd.defra.gov.uk

Pedelty, M. (2012). Ecomusicology: Rock, folk, and the environment. Temple University Press.

Pijanowski, B. C., Farina, A., Gage, S. H., Dumyahn, S. L., \& Krause, B. L. (2011). What is soundscape ecology? An introduction and overview of an emerging new science. Landscape Ecology, 26, 1213-1232. https://doi.org/10.1007/s10980-011-9600-8

Raimbault, M., \& Dubois, D. (2005). Urban soundscapes: Experiences and knowledge. Cities, 22(5), 339-350. https://doi.org/10.1016/j.cities.2005.05.003

Rudge, A. (2019). The sounds of people and birds: Music, memory and longing among the Batek of Peninsular Malaysia. Hunter Gatherer Research, 4(1), 2-23. https://doi.org/10.3828/hgr.2018.2

Samsuri A., Muhd Irfan A., Marzuki I., Ali N. A., Wan Nurdiyana W. M., \& Mohammad Fakhratul R. Z. (2019). Spatio-temporal analysis of environmental noise in institutional area. International Journal of Recent Technology and Engineering, 8(2), 4038-4042. https://doi.org/10.35940/ijrte.B3306.078219

Scarpelli, M. D. A., Ribeiro, M. C., Teixeira, F. Z., Young, R. J., \& Teixeira, C. P. (2020). Gaps in terrestrial soundscape research: It's time to focus on tropical wildlife. Science of the Total Environment, 707, 135403-135409. https://doi.org/10.1016/j.scitotenv.2019.135403

Schafer, R. M. (1977/1994). The soundscape: Our sonic environment and the tuning of the world. Destiny Books. 
Schafer, R. M. (2012-2013). Soundscape studies: The early days and the future. Soundscape: The Journal of Acoustic Ecology, 12(1), 6-8. https://www.wfae.net/uploads/5/9/8/4/59849633/soundscape_volume12.pdf

Schafer, R. M. (Ed.) (1977). Five village soundscapes. A.R.C. Publications.

Sethi, S. S., Jones, N. S., Fulcher, B. D., Picinali, L., Clink, D. J., Klinck, H., Orme, C. D. L., Wrege, P. H., \& Ewers, R. M. (2020). Characterizing soundscapes across diverse ecosystems using a universal acoustic feature set. Proceedings of the National Academy of Sciences of the United States of America, 117(29), 17049-17055. https://doi.org/10.1073/pnas.2004702117

Smalley, D. (2007). Space-form and the acousmatic image. Organised Sound, 12(1), 35-58. https://doi.org/10.1017/S1355771807001665

Smith, J. W., \& Pijanowski, B. C. (2014). Human and policy dimensions of soundscape ecology. Global Environmental Change, 28, 63-74. https://doi.org/10.1016/j.gloenvcha.2014.05.007

Sorce Keller, M. (2012). Zoomusicology and ethnomusicology: A marriage to celebrate in heaven. Yearbook for Traditional Music, 44, 166-183. https://doi.org/10.5921/yeartradmusi.44.0166

Southworth, M. (1969). The sonic environment of cities. Environment and Behavior, 1, 49-70. https://doi.org/10.1177/001391656900100104

Szeremeta, B., \& Zannin, P. H. T. (2009). Analysis and evaluation of soundscapes in public parks through interviews and measurement of noise. Science of the Total Environment, 407(24), 6143-6149. https://doi.org/10.1016/j.scitotenv.2009.08.039

Thomas, P., Aletta, F., Filipan, K., Mynsbrugge, T. V., De Geetere, L., Dijckmans, A., Botteldooren, D., Petrovic, M., Van de Velde, D., De Vriendt, P., \& Devos, P. (2020). Noise environments in nursing homes: An overview of the literature and a case study in Flanders with quantitative and qualitative methods. Applied Acoustics, 159, 107103107116. https://doi.org/10.1016/j.apacoust.2019.107103.

Thompson, E. (2002). Introduction: Sound, modernity, and history. In The soundscape of modernity: Architectural acoustics and the culture of listening in America, 1900-1933 (pp. 1-12). The MIT Press.

To, W. M., Chung, A., Vong, I., \& Ip, A. (2018). Opportunities for soundscape appraisal in Asia. Proceedings of Euronoise 2018.

http://www.euronoise2018.eu/docs/papers/484_Euronoise2018.pdf

Truax, B. (2002). Genres and techniques of soundscape composition as developed at Simon Fraser University. Organised Sound, 7(1), 5-14. https://doi.org/10.1017/S1355771802001024

Truax, B. (2012). Music, soundscape and acoustic sustainability. Möbius Journal, 1(1), 1-16. http://www.moebiusjournal.org/sites/default/files/upload/pdf/article/truax.pdf

Villanueva-Rivera, L. J., \& Pijanowski, B. C. (2012). Pumilio: A web-based management system for ecological recordings. Bulletin of the Ecological Society of America, 93, 71-81. https://doi.org/10.1890/0012-9623-93.1.71

Weidenaar, R. (2002). Composing with the soundscape of Jones Street. Organised Sound, 7(1), 65-72. https://doi.org/10.1017/S1355771802001103

Wrightson, K. (2000). An introduction to acoustic ecology. Soundscape: The Journal of Acoustic Ecology, 1(1), 10-13. https://www.wfae.net/journal.html 
Yang, M., \& Kang, J. (2013). Psychoacoustical evaluation of natural and urban sounds in soundscapes. The Journal of the Acoustical Society of America, 134(1), 840-851. https://doi.org/10.1121/1.4807800

Zainah M., Gurbinder K. J. S., Aishairma A., Nur Aishah A. M., \& Lalitha V. (2020). Constant disturbance in critical care units influenced patients' sleep quality. Sains Malaysiana, 49(2), 421-427. https://doi.org/10.17576/jsm-2020-4902-21

Zhang, M., \& Kang, J. (2007). Towards the evaluation, description, and creation of soundscapes in urban open spaces. Environment and Planning B: Urban Analytics and City Science, 34, 68-86. https://doi.org/10.1068/b31162

Zisiou, M. (2011). Towards a theory of museological soundscape design: Museology as a 'listening path'. Soundscape: The Journal of Acoustic Ecology, 11(1), 36-38. https://www.wfae.net/uploads/5/9/8/4/59849633/soundscape_volume11.pdf 